\title{
Analisis Kesenian Lodong Gejlig Di Kampung Sukatani Desamandalagiri Kecamatan Leuwisari Kabupaten Tasikmalaya
}

\author{
Vivi Hanifah Nurbaeti, Asep Wasta, Arni Priliani \\ Sendratasik Fakultas Keguruan dan Ilmu Pendidikan, Universitas Muhammadiyah Tasikmalaya, Jl. Tamansari \\ No. KM 2.5 Mulyasari Kec. Tamansari Tasikmalaya Jawa Barat \\ Indonesia. \\ Email: Vivihanifah119@gmail.com
}

\begin{abstract}
This scientific paper is entitled "Analysis of the Art of Lodong Gejlig in Sukatani Village, Mandalagiri Village, Leuwisari District, Tasikmalaya Regency." The art of Lodong Gejlig is always displayed in regent's receptions, harvest festivals, celebrations in celebration and for entertainment. This study aims to obtain data and information about 1). Form and presentation of lodong gejlig art in Kampung Sukatani, Mandalagiri Village, Leuwisari District, Tasikmalaya Regency. 2). Efforts to preserve the art of Lodong Gejlig in Kampung Sukatani, Mandalagiri Village, Leuwisari District, Tasikmalaya Regency.3). Development of Lodong Gejlig art in Sukatani Village, Mandalagiri Village, Leuwisari District, Tasikmalaya Regency. Lodong Gejlig is a combination of 2 words, namely "Lodong" and "Gejlig". lodong is a tool used to take kawung water while gejlig is a ground -breaking movement. The method used in this research is a qualitative method with a descriptive approach. Data collection techniques through, observation, interviews, documentation and literature study.
\end{abstract}

Keywords: Art, Lodong Gejlig.

\section{ABSTRAK}

Tulisan karya ilmiah ini berjudul " Analisis Kesenian Lodong Gejlig di Kampung Sukatani Desa Mandalagiri Kecamatan Leuwisari Kabupaten Tasikmalaya.” Kesenian Lodong Gejlig selalu ditampilkan dalam acara penyambutan bupati, panen raya, penyambutan dalam hajatan dan untuk hiburan. Penelitian ini bertujuan untuk memperoleh data dan informasi tentang 1). Bentuk dan penyajian kesenian lodong gejlig di Kampung Sukatani Desa Mandalagiri Kecamatan Leuwisari Kabupaten Tasikmalaya. 2). Upaya pelestarian kesenian Lodong Gejlig di Kampung Sukatani Desa Mandalagiri Kecamatan Leuwisari Kabupaten Tasikmalaya.3). Pengembangan kesenian Lodong Gejlig di Kampung Sukatani Desa Mandalagiri Kecamatan Leuwisari Kabupaten Tasikmalaya. Lodong Gejlig adalah gabungan dari 2 kata yaitu "Lodong” dan "Gejlig". lodong merupakan alat yang digunakan untuk mengambil air kawung sedangkan gejlig adalah sebuah gerakan hempasan ketanah. Metode yang digunakan dalam penelitian ini adalah metode kualitatif dengan pendekatan deskriptif. Teknik pengumpulan data melalui, observasi, wawancara, dokumentasi dan studi pustaka.

Kata kunci : Kesenian, Lodong Gejlig.

\section{A. Pendahuluan}

Kesenian merupakan bagian dari kebudayaan yang mempunyai ciri khas sendiri antara daerah satu dengan yang lainnya. Oleh karena itu, kesenian dijadikan sarana untuk mengekspresikan jiwa manusia dan mempunyai nilai - nilai keindahan. Menurut Hatta (2010) dalam Hanif, Muhammad, dkk (2018:1) "Kesenian merupakan salah satu bagian penting dari kebudayaan." Pernyataan lain tentang kesenian seperti diungkapkan oleh Berlian,Zainal
(2020:100) "Kesenian merupakan bagian dari budaya dan sarana yang digunakan untuk mengekspresikan rasa keindahan dari dalam jiwa manusia, keindahannya juga mempunyai fungsi lain."

Daerah Tasikmalaya merupakan sebuah daerah yang kuat akan kesenian dan kebudayaanya terlihat dari keberagaman bahasa, adat istiadat dan keyakinannya. Seperti halnya Kesenian Lodong Gejlig yang berada di kampung Sukatani desa Mandalagiri. 
Kesenian Lodong Gejlig merupakan kesenian tradisional yang berasal dari aktivitas masyarakat sunda yang hidup diperkampungan yaitu bertani atau berhuma yang berasal dari kampung Sukatani desa Mandalagiri. Kampung Sukatani berada di pinggir gunung Galunggung yang secara tidak langsung masyarakat disana kebanyakan mata pencahariannya sebagai petani, yang salah satunya berhuma atau masyarakat menyebutnya nyadap kawung (mengambil air nira / aren) kegiatan ini ada yang untuk konsumsi pribadi atau untuk dijual kembali untuk menghidupi keluarga, karena di desa ini banyak sekali pohon kawung.

Untuk menyadap kawung ini masyarakat membuat sebuah alat untuk mempermudah mereka melakukan penyadapan. Alat ini terbuat dari sebuah bambu yang kemudian di potong dan petani menyebutnya lodong. untuk memastikan tidak ada kebocoran pada alat tersebut maka petani akan menghempaskan dulu ketanah jika lodong itu ada kebocoran maka tidak akan berbunyi, dari sinilah ada seorang masyarakat yang mempunyai sebuah ide untuk menciptakan sebuah kesenian tradisional dari aktifitas sehari - hari yaitu berhuma. Kesenian ini tidak mempunyai nada seperti kesenian lainnya, nada yang dihasilkan itu dari ketukan lodong ke tanah, inilah yang menjadi keunikan kesenian ini. Dengan adanya kesenian ini masyarakat mempunyai hiburan untuk melepaskan kepenantan setelah seharian bekerja. Karena cara memainkan kesenian ini dihempaskan atau digejligkan ketanah maka diberi nama Lodong Gejlig.

Seiring dengan perkembangan jaman kesenian Lodong Gejlig mengalami perubahan karena sudah tercampur dengan kesenian barat sehingga sekarang kesenian Lodong Gejlig jarang sekali ditampilkan hanya menggunakan Lodong saja namun dikolaborasikan dengan alat musik barat. Maka dari itu kesenian Lodong Gejlig ini perlu dilestarikan supaya tidak terlupakan oleh masyarakat karena semakin berkembangnya jaman. Banyak anak anak remaja yang terpengaruh oleh perkembangan jaman seperti memainkan Tiktok menarikan dance dance Tiktok tetapi tidak bisa menarikan tarian tradisional banyak juga yang pandai memainkan alat musik modern tetapi tidak bisa memainkan alat musik tradisional. Sehingga kesenian tradisional tersisihkan maka dari itu perlu upaya untuk melestarikan kesenian tradisional dengan mengajak generasi - generasi muda untuk ikut dalam pengembangan kesenian tradisional dan memanfaatkan fasilitas yang ada yaitu sosial media yang mereka miliki. Pemerintah juga melakukan pengembangan dan pelestarian kesenian tradisional dengan mengadakan acara pentas budaya yang mengundang berbagai kesenian tradisional yang ada di tasikmalaya yang salah satunya Lodong Gejlig.

Kelebihan dari kesenian ini adalah menunjukan ciri kebudayaan masyarakat yang mata pencahariannya huma / berladang. Kesenian ini meski mengalami pasang surut namun tetap eksis dilestarikan karena banyak masyarakat menyukai kesenian ini yang ditampilkan pada perayaan tertentu diantaranya hajatan, sunatan, perayayaan hari kemerdekaan RI sebagai hiburan yang di nikmati oleh para pencintanya maka dari itu kesenian ini layak untuk diteliti.
B. Pembahasan
1. Bentuk Penyajian Kesenian lodong Gejlig 
Bentuk penyajian adalah wujud dari beberapa unsur penyajian yang digunakan sebagai alat komunikasi untuk menyampaikan, menghidangkan, menyajikan atau suatu pesan tertentu dari pencipta kepada masyarakat atau suatu komposisi untuk menghasilkan struktur dalam maupun luar serta prinsip yang memberikan kesatuan secara menyeluruh sehingga dapat dilihat dan dinikmati khususnya Kesenian Lodong Gejlig. Menurut Majid, Abdul, (2015:15) “ penyajian adalah cara untuk memaparkan dan menampilkan sesuatu bentuk secara menyeluruh."

Kesenian Lodong Gejlig biasanya ditampilkan pada ruangan terbuka yang beralaskan tanah atau benda padat agar Lodong Tersebut memberikan bunyi. Seperti seni pertunjukan lainya kesenian Lodong Gejlig sebelum melakukan pementasan para pemain kesenian Lodong Gejlig selalu berlatih terlebih dahulu kemu dian ada hal - hal yang harus di persiapkan yaitu alat pelengkap yaitu tatakan yang digunakan jika tampil nya tidak ditanah karna kesenian ini harus beralakan tanah atau semen jika beralaskan panggung dari kayu atau papan tidak akan berbunyi, dan properti lainya.

Kesenian Lodong Gejlig tidak membutuhkan Lighting karena biasanya kesenian ini selalu ditampilkan di tempat terbuka yang beralaskan tanah. Agar suara keras maka diperlukan mik yang ditempelkan pada lodong tersebut. Sebelum dilakukan nya pertunjukan biasanya bapak Usep akan memanjatkan tawasul dulu kepada leluhur Galunggung I sesepuh yang sudah meninggal dan kepada Alloh SWT agar di lancarkan. Seperti yang diungkapkan oleh bapak Usep " sateacan tampil biasa latihan heula tawasul setting alat - alat saatos kitu langsung tampil, upami dinu hajat pribadi ku bapa di tawasulan heula tanpa sepengetahuan orang, upami dina acara umum, sapertos hajat lembur, pesta laut tah ieu mah aya ritual nganggo menyan mediana tujuan na tetep ka Alloh sareng karuhun - karuhun nu tos teu aya." Sebelum tampil mereka selalu berlatih dahulu kemudian dilanjutkan berdoa, setting alat - alat sesudah itu langsung tampil, kalau pada acara lainnya yang lebih umum seperti syukuran pribadi sama saya didoakan dulu tanpa sepengetahuan orang lain, kalau di acara umum seperti syukuran kampung, pesta laut, ada ritual khusus memakai media kemenyan tetapi tujuannya tetap kepada alloh SWT sama nenek monyang yang sudah meninggal.

Setelah semua kebutuhan lengkap berarti tahap persiapan selesai tinggal menunggu pertunjukan Lodong Gejlig. Diawali dengan beberapa tabuhan Lodong kemudian membawakan lagu Seni Buhun. Setelah selesai pertunjukan biasanya di adakan sesi wawancara mengenai kesenian Lodong Gejlig.

2. Unsur pendukung pada Kesenian Lodong Gejlig

a) Instrumen Musik

Instrumen musik yang digunakan pada kesenian Lodong Gejlig ini yaitu sebuah Lodong. Lodong merupakan alat yang tadinya dipakai sehari - hari untuk menyadap kawung. Kesenian ini bisa di tampilkan hanya lodong saja bahkan bisa dengan bantuan alat musik lain nya seperti terompet, angklung, gamelan, keayboard. Kesenian Lodong Gejlig ini berbentuk bambu tidak mengubah unsur asli bambunya, bambu tersebut di potong kemudian di haluskan supaya pada saat memegang tidak terluka karena ada serat bambu yang ada pada sambungan nya kemudian bambu yang sudah dipotong dan dibersihkan di lubangi bagian dalamnya kemudian dibuang sedikit atasnya. 
b) Unsur Musik

1) Melodi

Melodi adalah susunan beberapa nada yang teratur tinggi - rendahnya sehingga terdengar berirama sehingga menjadi sebuah lagu. Memainkan melodi sama dengan memainkan notasi notasi dalam kerangka notasi lagu tanpa syair (disebut juga dengan instrumental). Melodi merupakan unsur pokok dalam musik yang menjadi pusat perhatian bagi para penikmat musik. Menurut Rizky, Amelia Idhartono (2021 : 82) " Melodi merupakan susunan rangkaian nada (bunyi dengan getaran teratur) yang terdengar berurutan dan berirama. Melodi yang digunakan pada kesenian Lodong Gejlig hanya terdapat pada vokal yang dilantunkan para pemain Lodong Gejlig, karena Lodong Gejlig tidak mempunyai nada dan bunyi yang di keluarkan hanya berupa dong dong.

2) Harmoni

Harmoni merupakan pendukung dari melodi dan biasanya terdiri dari dua notasi lebih atau tiga dan dibunyikan secara bersamaan. Harmoni adalah perpaduan bunyi dari permainan musik yang menggunakan nada atau lebih dan memiliki perbedaan antara tinggi dan rendahnya suatu nada pada bunyi yang dimainkan secara bersamaan sehingga menghasilkan suara yang indah. Menurut Banoe, dalam Wira, Komang,Adhi,Mahardika (2020:24) : "Harmoni adalah cabang ilmu pengetahuan musik yang membahas dan membicarakan perihal keindahan komposisi musik".

Harmoni dalam kesenian Lodong Gejlig ditunjukan dengan perpaduan dan kekompakan alat musik ritmisnya. Harmonisasi musik Lodong Gejlig dilihat dari keselarasan asli musik Lodong Gejlig dan vokal yang dilantunkan didalamnya.

3) Irama

Irama adalah alunan bunyi yang teratur dan berulang-ulang dan dianggap denyut jantung musik. Menurut Joseph dalam Rizky, (2021 : 82), " irama adalah gerak musik yang teratur secara tidak tampak dalam lagu melainkan dapat dirasakan setelah lagu tersebut dialunkan". Irama pada kesenian Lodong Gejlig terlihat dari ketukan lodongnya. Berikut adalah Irama atau pola tabuhan Lodong Gejlig beserta liriknya.

4) Syair

Syair lagu dalam kesenian Lodong Gejlig dari bahasa sunda.

5) Anggota pemain kesenian Lodong Gejlig

Anggota pemain kesenian Lodong Gejlig adalah unsur terpenting dalam keenian Lodong Gejlig karena apabila tidak ada pemain maka kesenian ini tidak akan berjalan dengan baik. Terdapat 5-7 orang pemain kesenian Lodong Gejlig dimana maing maing pemain memiliki tugas dan peran nya maing - masing, diantaranya yaitu : Wendi Nugraha, Faisal Wildan, Farhan Muhammad Syam, Fikri Muhammad Rizqi, M. Zaki Aljabarri, Misbah, Uneng Suryani.

6) Vokal

Vokal dalam kesenian Lodong Gejlig adalah bagian yang penting karena sudah merupakan kesatuan dari pertunjukan kesenian Lodong Gejlig itu sendiri.Lodong Gejlig disajikan dengan iringan musik yang khas disertai lagu seni buhun. Tidak banyak variasi dalam vokal yang dibawakan, semua yang memainkan 
Lodong Gejlig juga ikut menyanyikan bersama mengikuti iringan musik tanpa ada tingkatan suara.

7) Busana

Busana adalah salah satu benda yang digunakan masyarakat dalam kehidupan sehari - hari. Busana tradisional wanita sunda adalah kain / sinjang atau kebaya sunda, sedangkan untuk laki - laki kampet. Sehingga para pemain Lodong Gejlig memakai kebaya dan samping sedangkan laki - laki memakai kampret.

\section{Pengembangan Kesenian Lodong Gejlig}

Sebuah kesenian dapat mengalami perkembangan. Dengan mengikuti zaman yang modern ini Kesenian Lodong Gejlig dari tahun 1991 - sekarang mengalami perubahan dan perkembangan yang baik. Awalnya dari sebuah alat menyadap kawung menjadi kesenian Lodong Gejlig. Kesenian ini pada mula nya oleh bapak Elon Dahlan dikolaboraikan dengan Gitar yang terbuat dari seng dan dinamai tardong kemudian kesenian ini diteruskan oleh bapa Usep Tatan Turyana S.pd diubah namanya menjadi Lodong Gejlig karna mengingat cara memainkan kesenian ini dengan cara dihempaskan ketanah. Kemudian bapak Usep membuat sebuah wadah dengan mendirikan nya sebuah sanggar yang langsung dipimpin oleh beliau sendiri yaitu Sanggar Sekar Galih.

Sesuai perkembangan jaman kesenian Lodong Gejlig mengalami beberapa perubahan diantaranya alat musik gitar yang terbuat dari seng itu sudah langka maka Lodong Gejlig dimainkan dengan Lodong saja tetapi, banyak permintaan dari masyarakat kesenian Lodong Gejlig di kolaborasi kan dengan alat kesenian lainnya seperti gamelan yang sampai sekarang masih digunakan. Bahkan sekarang ada yang dikolaborasikan dengan instrumen keyboard (organ)yang digunakan sebagai patokan untuk bernyanyi pada beberapa lagu contohnya pada lagu Gerbang Desa. Kesenian Lodong Gejlig sudah banyak dikenal mayarakat yang digunakan sebagai mengisi berbagai acara seperti hajatan, prosesi penerimaan tamu pejabat, syukuran panen raya, hajat laut.

Kesenian Lodong Gejlig merupakan kesenian tradisional Sunda yang perlu dijaga dan dilestarikan sehingga kesenian ini terus berkembang dan tetap eksis. Kesenian Lodong Gejlig ini di wariskan kepada generasi - generasi muda yang ingin belajar kesenian ini karena kesenian Lodong Gejlig ini mudah untuk dimainkan. Kesenian Lodong Gejlig seiring perkembangan globalisasi sekarang banyak mengalami perubahan dengan di kombinasikan dengan alat alat kesenian lainya baik itu alat kesenian tradisional maupun modern.

Kesenian yang hidup dan berkembang pada lapisan masyarakat secara tidak langsung mempunyai pengaruh yang cukup besar bagi para pelaku seni, masyarakat pendukungnya. Hal ini terjadi karena adanya kesadaran dalam diri masyarakat untuk ikut mendukung kesenian tersebut agar terus berkembang dan tidak terlupakan karena adanya pengaruh musik modern. Berikut ini beberapa aspek yang mempengaruhi perkembangan kesenian Lodong Gejlig diantaranya .

a. Lapisan Masyarakat

Pengaruh yang signifikan yang terjadi dalam kesenian ini adalah warga kampung Sukatani dan sekitarnya ikut serta dalam pengembangan kesenian ini dengan ikut berperan serta menjadi pemain dalam kesenian Lodong Gejlig. Hal utama yang paling berpengaruh adalah tidak adanya batasan usia dari para pemainnya dan yang paling 
berperan adalah dari kalangan generasi muda karena untuk tetap lestarinya kesenian Lodong Gejlig.

b. Pendidikan

Pendidikan pada suatu wilayah sangat ditekankan demi terciptanya masyarakat yang cerdas. Dalam kesenian Lodong Gejlig mempunyai pesan pendidikan didalamnya para pemain kesenian Lodong Gejlig harus saling menghormati baik itu kepada orang tua , sebaya bahkan kepada yang lebih muda dan tidak memandang rendah satu sama lain. Pada saat latihan secara tidak langsung kesenian ini mengajarkan bagaimana kita berkesenian bagaimana kita mengharmonikan sebuah alat musik yang tidak mempunyai nada agar terdengar dengan indah. Kesenian Lodong Gejlig juga sudah menjadi bahan ajar di sebuah SD Mekarjaya yang ada di kampung Sukatani dan gurunya merupakan pembina kesenian Lodong Gejlig itu sendiri.

\section{Kesimpulan}

Berdasarkan hasil dari penelitian lapangan kesenian Lodong Gejlig di Kampung Sukatani desa Mandalagiri kecamatan Leuwisari kabupaten Tasikmalaya dapat disimpulkan bahwa masyarakat di kampung Sukatani pada umumnya bermata pencaharian sebagai petani / berhuma yang berasal dari kebiasaan orang sunda. Hal ini sesuai dengan ilmu antropologi.

Di kampung ini banyak sekali pohon kawung sehingga mata pencahariannya menyadap kawung. Dari sebuah kebiasaan ini masyarakat di kampung Sukatani ini membuat sebuah kesenian tradisional dan menjadi sebuah identitas daerah kampung Sukatani. Sesuai dengan ilmu etnomusikologi
Lodong Gejlig merupakan kesenian tradisional yang terbuat dari sebuah bambu Sudat atau Gombong yang kemudian dipotong sesuai ukuran yang dibutuhkan untuk satu paket kesenian Lodong Gejlig dibutuhkan satu batang bambu. Kesenian Lodong Gejlig dimainkan $5-7$ orang pemai dan masing masing pemain memiliki tugas masing masing. Alat yang digunakan dalam permainan Lodong Gejlig yaitu Bass 1 , Bass 2, Bass 3, Rincik, Kotek, dan Lodong Pelengkap. Hal ini sesuai dengan ilmu organologi

Di kampung sukatani masyarakat sangat kompak terlihat ketika kesenian ini tampil masyarakat sangat antusias sekali menyerahkan hasil tani mereka kepada para pemain dan tamu yang datang dalam melihat kesenian Lodong Gejlig. Dan para masyarakat juga berbondong bondong untuk melihat kesenian ini tampil. Masyarakat juga aktif dalam kegiatan PKK dan juga selalu berkumpul untuk mengadakan pesta panen raya. Hal ini sesuai dengan ilmu sosiologi.

Kesenian Lodong Gejlig ini di lestarikan di Sanggar Sekar Galih dimana pelatihnya pencipta kesenian Lodong Gejlig ini kesenian ini dapat sponsor dari roko Gudang Patra bahkan dari pemerintah setempat juga mensponsori kesenian ini dan apabila ada acara - acara kesenian ini akan selalu tampil untuk membuka acara tersebut. Kesenian Lodong Gejlig sudah ditampilkan oleh generasi - generasi muda sehingga kesenian ini akan terus berkembang dan menjadi salah satu warisan budaya yang ada di Indonesia maka dari itu kita harus menjaga ke aslian kesenian ini.

\section{Daftar Pustaka}


Banoe, (Wira, Komang, Adhi, Mahardika 2020) pengantar karya musik Chamber "Kacang Dari". Indramayu: CV. Adanu Abimata

Berlian, zainal (2020), Ilmu Alamiah Dasar, Ilmu Budaya Dasar, dan Ilmu Sosial. Malang: Intelegensia Media

Hatta, (2010), (Hanif, Muhammad, dkk 2018) Panduan Pelaksanaan Model Nampe, Menginternalisasi Nilai Kesenian Dongkrek Guna Meningkatkan Ketahanan Budaya Siswa SMA. Yogyakarta : Deepublish

Joseph, (Rizky,2021), Pembelajaran Musik Dan Tari Anak Berkebutuhan Khusus, Solok : INSAN CENDEKIA MANDIRI

Majid, Abdul (2015) Eksistensi, Bentuk Penyajian dan Fungsi Kesenian Tradisional Orek - Orek di Kabupaten Rembang. Semarang: Darmawan Aji. 